\title{
Validation of a flame photometric method for serum lithium estimation
}

\author{
U Mannapperuma ${ }^{1}, \mathrm{C}$ M Peiris ${ }^{1}$, D Thambawita ${ }^{1}$, P Galappatthy ${ }^{1}, \mathrm{C}$ D Pathiranage ${ }^{1}$, A Lionel ${ }^{1}, \mathrm{R}$ L \\ Jayakody $^{1}$ \\ ${ }^{1}$ Department of Pharmacology, University of Colombo, Sri Lanka
}

\author{
Article Information \\ Total number of \\ Words: 2905 \\ Tables: 4 \\ Figures: 2 \\ Authors have no conflicts of interest to \\ declare \\ Key words: Lithium carbonate, \\ Flame photometry, Therapeutic drug \\ monitoring, Validation
}

Date of Submission: 04.02.2017

Date of acceptance : 10.01.2018

DOI:

http://doi.org/10.4038/cjms.v54i2.4824

Author responsible for correspondence: Uthpali Mannapperuma Department of Pharmacology, Faculty of Medicine

No.25, Kynsey Road, Colombo 08. uthpalim@yahoo.com

http://orcid.org/0000-0002-7433-2855

\begin{abstract}
Background

Lithium is a first line drug used to treat bipolar affective disorder requiring frequent monitoring due to its narrow therapeutic index. Flame photometry is a reliable quick and cost-effective method of serum lithium estimation.
\end{abstract}

\section{Objective}

We aimed to validate a flame photometry method for serum lithium estimation to compare the results with a different model flame photometer and an ionselective electrode.

\begin{abstract}
Method
Sherwood 410 flame photometer was used for the analysis. Serum samples were diluted 1:2 using a lithium blank solution containing sodium and potassium. Aqueous lithium standards were prepared using the same blank. The method was validated for the concentration range $0.2-1.5 \mathrm{mmol} / \mathrm{l}$. Linearity, recovery, accuracy, precision and stability were determined by standard lithium serum samples representing the lower limit of quantification (LLOQ) $0.2 \mathrm{mmol} / 1$, median level of quantification (MLOQ) $0.8 \mathrm{mmol} / \mathrm{l}$ and the upper limit of quantification (ULOQ) $1.5 \mathrm{mmol} / 1$. Five replicates of serum and aqueous lithium samples were used to determine linearity in the range between LLOQ and ULOQ using the coefficient of determination (R2). Five standard serum replicates were used for recovery, accuracy and precision studies. Precision was determined by the coefficient of variation $(\mathrm{CV} \%)$ on three different days. Results of the flame photometric method were compared with those of a different flame photometric method and an ion-selective electrode method.
\end{abstract}

Results: The R2 for the aqueous samples and the serum samples was $>0.995$ demonstrating linearity. The matrix effect ranged between $92.5 \%$ and $105 \%$ for the LLOQ, MLOQ and ULOQ. The accuracy and precision for LLOQ, MLOQ of and ULOQ were below 15\%. Similar results were obtained for the QC samples with the different model flame photometer and ion-selective electrode method.

\section{Conclusion}

The flame photometric method used in our laboratory is suitable and reliable for determining serum lithium concentrations for use in therapeutic drug monitoring.

\section{Background}

Lithium is of proven efficacy in the treatment of bipolar disorder showing benefit in both the manic phase and the depressive phase. It is also effective in the prophylaxis of the condition [1-2].
In order to manage these patients on lithium therapy better, it is recommended to monitor their serum lithium concentrations. Such monitoring helps to optimize therapy, confirm adherence and detect toxicity. As there are intra-individual variations in the response to lithium therapy, 
serum lithium concentrations provide good information to prescribers to maintain effective concentrations of the drug in the patients. Serum lithium concentrations are monitored at initiation of therapy for dose adjustment. As maintenance therapy, serum lithium concentrations are recommended to be measured every 3-6 months for optimum therapeutic drug monitoring [2-3]. Trough concentrations of lithium are recommended to be measured typically 12 hours post dosing. Serum lithium concentrations are affected by coadministered drugs such as carbamazepine and are also affected by changes in renal function [1-2]. Adverse effects are observed at the therapeutic range, as well as when the serum concentrations exceed the therapeutic range in a dose dependent manner [1].

As lithium is a drug with a narrow therapeutic index it is important to determine serum lithium concentrations by an accurate method as patient safety is improved by maintaining the serum concentrations within the therapeutic range, while dose adjustments can be done if toxic concentrations are detected. Many methods are employed to determine the serum lithium concentrations. As reported in literature, photometric methods such as flame photometry, flame atomic absorption spectrophotometry and colorimetry are widely used, while ion-selective electrodes are also used to determine lithium concentrations [4-7]. Among these methods flame photometry is regarded as a simple, rapid and cost-effective method.

This study describes the validation of a flame photometric method which is performed under conditions modified from the manufacturer's recommendations for analysis of serum lithium. This method is used for the therapeutic drug monitoring of Lithium, at the laboratory of the Department of Pharmacology, Faculty of Medicine, University of Colombo. Validation of the method was planned in order to confirm the reliability of the results generated as clinical decisions are made based on the reports generated by the flame photometric method used by the Department laboratory.

\section{Objectives}

The primary objective of the study was to validate a flame photometry method for serum lithium estimation according to the European Medicines Agency guidance on bioanalytical method validation [8]. We further planned to compare the results obtained from the Sherwood 410 Flame photometer with a different flame photometric method and an ion-selective electrode method.

\section{Methodology \\ Instrumentation and reagents}

The instrument used was a flame photometer (Model 410 Sherwood Scientific Ltd, Cambridge, UK). The 410 model flame photometer does not contain a built-in diluter. Therefore, manual dilution was used with the aid of micropipettes prior to sample aspiration into the flame photometer. All serum and calibration solutions are diluted to one third of its initial concentration using an aqueous "lithium blank solution". The blank solution was used as sodium and potassium found in serum is known to cause enhancement of the lithium emission during flame photometric analysis [9].

The instrument was calibrated with Sherwood standard solution which is traceable to lithium reference materials NIST $917 \mathrm{~b}$ and NIST 965a, a Multical standard ( $1.5 \mathrm{mmol} / \mathrm{l}$ lithium concentration). Other chemicals and solutions used in the analysis were of a grade suitable for trace metal analysis and were purchased from Sigma-Aldrich company. Deionized water was used for the reagent preparation.

\section{Standard solutions}

A stock solution of lithium at $100 \mathrm{mmol} / \mathrm{l}$ was prepared by dissolving $3.6941 \mathrm{~g}$ of lithium carbonate standard in a $1000 \mathrm{~mL}$ grade A volumetric flask with a solution containing $100 \mathrm{ml}$ of $4 \mathrm{M}$ hydrocholoric acid in de-ionized water. A lithium working solution of $2 \mathrm{mmol} / \mathrm{l}$ was made from the lithium stock solution. The lithium working solution was diluted to prepare six calibration solutions covering the concentration range $0.2-1.5 \mathrm{mmol} / \mathrm{l}$ using the lithium blank solution which contained $140 \mathrm{mmol} / \mathrm{l}$ of sodium and $5 \mathrm{mmol} / \mathrm{l}$ potassium. This concentration range was selected to cover the subtherapeutic, therapeutic and toxic concentrations of serum lithium [10].

To determine the accuracy and the precision of the method, quality control samples were prepared. The quality control (QC) samples consisted of three standard lithium concentrations in serum. Serum standards of the lower limit of quantification (LLOQ) - $0.2 \mathrm{mmol} / \mathrm{l}$, median level of quantification (MLOQ) $-0.8 \mathrm{mmol} / \mathrm{l}$ and upper limit of quantification (ULOQ) - $1.5 \mathrm{mmol} / \mathrm{l}$ were used. The LLOQ of $0.2 \mathrm{mmol} / \mathrm{l}$ was selected as it was the lowest concentration for which the flame photometric response was detected. The ULOQ represents the limit of over dosage with lithium [11]. These standards were prepared by spiking blank pooled serum from a 
stock serum solution of lithium carbonate with a concentration of $4 \mathrm{mmol} / \mathrm{l}$. All samples were diluted 1:2 using the lithium blank solution before aspiration to the flame photometer.

\section{Determining the lower limit of quantification and lower limit of detection}

The lower limit of quantification was calculated as 10 times the residual standard deviation of a regression line divided by the slope of the calibration curve [12]. Six replicates of the calibration standards at six concentrations raging from $0.2-1.5 \mathrm{mmol} / \mathrm{l}$ were used for this calculation. A quantification limit of $0.12 \mathrm{mmol} / \mathrm{l}$ was calculated as the lower limit of quantification. A lower limit of quantification used for this validation study was 0.2 $\mathrm{mmol} / \mathrm{l}$ as the objective of the study was to validate serum lithium concentrations in the therapeutic range where values less than $0.2 \mathrm{mmol} / \mathrm{l}$ are less significant with respect to patient management. The accuracy and precision of the selected lower limit of quantification was validated with respect to accuracy, precision and stability.

\section{Determination of the matrix effect}

Lithium spiked aqueous solutions and serum solutions of $0.2 \mathrm{mmol} / 1,0.8 \mathrm{mmol} / \mathrm{l}$ and $1.5 \mathrm{mmol} / \mathrm{l}$ concentrations were prepared separately and diluted 1:2 with the lithium blank solution. Five replicates for each sample were aspirated to the flame photometer and readings were taken. The "matrix factor" was calculated by calculating the ratio of readings of the lithium spiked serum samples to aqueous samples. The matrix factor calculated for each five replicates not greater than $15 \%$ was determined as demonstrating minimum matrix effect for the aqueous calibration plots and serum QC samples and the patient samples analysed [8].

\section{Determination of linearity}

The linearity study was carried out by assaying the linearity of the calibration plot prepared by using six standard aqueous lithium solutions with five replicates. The concentrations were between the LLOQ and the ULOQ. Linear regression was used to determine the linearity of the calibration plot. A coefficient of determination $\left(\mathrm{R}^{2}\right)>0.995$ was considered as acceptable linearity. The concentration of each calibration standard was back calculated and a concentration within $\pm 15 \%$ of the nominal value was considered acceptable [8].

\section{Determination of accuracy and precision}

Intra-day and inter-day variation of accuracy and precision was determined as three different runs, for five replicates of the quality control samples of LLOQ, MLOQ and ULOQ over a period of four weeks. Accuracy was calculated as a percentage deviation between the calculated concentration and the theoretical concentration of each QC sample. A percentage deviation (percentage bias) within $15 \%$ of the actual value was determined as acceptable accuracy [8]. Precision was determined at each concentration by determination of the coefficient of variation $(\mathrm{CV})$. For the LLOQ, a $\mathrm{CV}$ below $15 \%$ was considered acceptable [8].

\section{Determination of freeze-thaw stability}

Three replicates per each QC samples were stored at the storage temperature of $-20^{\circ} \mathrm{C}$ for 24 hours and then allowed to thaw at room temperature. Each sample was refrozen. This freeze thaw cycle was repeated two more times. The samples were frozen between 12-24 hours during the freeze thaw cycles. Concentrations of the samples were determined and a calculated concentration within $15 \%$ of the nominal concentration (percentage bias) was used to demonstrate freeze-thaw stability [8].

\section{Long term stability}

Concentrations of five replicates of each of the QC samples stored at $-20^{\circ} \mathrm{C}$ for one month were assayed to determine long term stability of samples. A calculated concentration within $15 \%$ of nominal concentration (percentage bias) was used to determine long term stability [8].

\section{Bench top stability and stability of the processed samples}

Three replicates per each QC sample were kept undiluted to determine the bench top stability and another five replicates of each QC sample were diluted at a ratio 1:2 with the lithium blank solution. The undiluted samples were kept at room temperature for five hours and the diluted samples were kept for six hours and the flame photometric readings were taken. A concentration within $15 \%$ of the nominal concentration (percentage bias) was used as demonstrating bench top stability and stability of the processed sample [8].

\section{Inter-laboratory comparison}

Three aliquots of each QC sample concentration were analysed by a flame photometer

(Jenway PFP7 flame photometer, Jenway Ltd., Felsted, Dunmow, Essex, UK) at the Analytical Laboratory of the Department of Chemistry, Faculty of Science, University of Colombo and a separate set of samples were analysed by an ion-selective electrode method at a private sector laboratory having ISO 15189:2012 accreditation. The samples 
analysed by the ion-selective electrode method were sent to the laboratory without any indication of the concentration of each sample, and were analysed as routine clinical samples.

\section{Analysis of patient samples}

The validated method was applied for the determination of serum lithium concentration in patients arriving for therapeutic drug monitoring. The following data are from 240 adults who were on steady doses of lithium carbonate therapy and had taken the last dose of lithium 12 hours prior to blood sampling.

\section{Results}

\section{Matrix effect}

Results of the matrix effect study are given in Table 1. The calculated matrix factors ranged from 92.5$105 \%$ demonstrating minimum effect from the serum matrix in flame photometric quantification of lithium in serum.

Table 1: Matrix effect determination between aqueous and serum lithium quality control samples

\begin{tabular}{lccc}
\hline $\begin{array}{l}\text { Nominal } \\
\text { lithium } \\
\text { concentration } \\
\text { (mmol/l) }\end{array}$ & $\begin{array}{c}\text { Average } \\
\text { detector } \\
\text { response of } \\
\text { aqueous } \\
\text { lithium } \\
\text { samples } \\
(\mathbf{n = 5})\end{array}$ & $\begin{array}{c}\text { Average } \\
\text { detector } \\
\text { response } \\
\text { of serum } \\
\text { lithium } \\
\text { samples } \\
(\mathbf{n = 5})\end{array}$ & $\begin{array}{c}\text { Matrix } \\
\text { factor } \\
(\%)\end{array}$ \\
0.2 & 8 & 7.4 & $92.5 \%$ \\
0.8 & 32.2 & 32 & $99.4 \%$ \\
1.5 & 60 & 63 & $105.0 \%$ \\
\hline
\end{tabular}

\section{Linearity}

Both the aqueous and serum lithium solutions demonstrated a concentration-response relationship with the $\mathrm{R}^{2}$ values more than 0.995 demonstrating linearity (Figures 1 and 2). The back calculated concentrations of the calibration standards were within $\pm 15 \%$ of the nominal value.

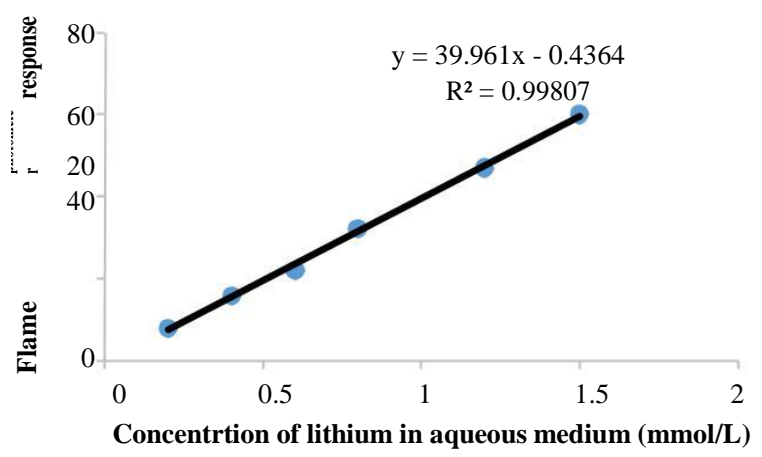

Figure 1. Flame Photometer response Vs Lithium concentration $(\mathrm{mmol} / \mathrm{l})$ in aqueous medium

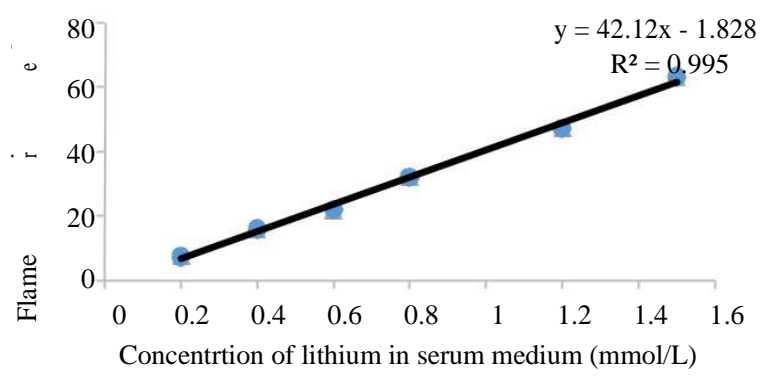

Figure 2. Flame Photometer response Vs

Lithium concentration $(\mathrm{mmol} / \mathrm{l})$ in serum

\section{Accuracy and Precision}

All QC samples demonstrated accuracy between 96.9-106.5\% of the nominal concentration of each sample with a CV ranging from 0-10.9\% (Table 2).

Table 2. Accuracy and Precision of the lithium quality control samples

\begin{tabular}{clccc}
\hline $\begin{array}{c}\text { Nominal lithium } \\
\begin{array}{c}\text { Concentration } \\
(\mathbf{m m o l} / \mathbf{l})\end{array}\end{array}$ & \multicolumn{1}{c}{ Variable } & First Analysis & Second Analysis & Third Analysis \\
\hline 0.2 & Measured concentration $(\mathrm{mmol} / \mathrm{l})$ & $0.20 \pm 0.01$ & $0.19 \pm 0.02$ & $0.21 \pm 0.01$ \\
& CV\% & 7 & 10.9 & 5.3 \\
& Accuracy \% & 98.1 & 96.0 & 104.4 \\
\hline 0.8 & Measured concentration $(\mathrm{mmol} / \mathrm{l})$ & $0.81 \pm 0$ & $0.80 \pm 0.02$ & $0.80 \pm 0.02$ \\
& CV\% & 0 & 2.8 & 2.8 \\
& Accuracy \% & 101.5 & 99.9 & 99.9 \\
\hline 1.5 & Measured concentration $(\mathrm{mmol} / \mathrm{l})$ & $1.59 \pm 0.04$ & $1.57 \pm 0.014$ & $1.60 \pm 0.08$ \\
& CV\% & 2.2 & 2.9 & 5.1 \\
& Accuracy \% & 105.8 & 106.5 & 106.5 \\
\hline
\end{tabular}




\section{Stability}

Table 3 summarizes the stability results obtained from freeze-thaw, long term, bench top and processed sample stability studies. All samples

Comparison of the Sherwood 410 analyser results with Jenway PFP7 analyser and the ion-selective electrode method

Results obtained by the two different methods are given in Table 4. Both flame photometric method of Jenway PFP7 and ion-selective electrode method demonstrated acceptable stability with a percentage bias less than $10 \%$.

employed at the private sector laboratory demonstrated similar results to both the nominal concentration of the sample and the concentration demonstrated by the Sherwood 410 Flame photometer.

Table 3. Results of the stability of the lithium quality control samples expressed as bias

\begin{tabular}{ccccc}
\hline & \multicolumn{2}{c}{$\%$ Bias \% } \\
\hline $\begin{array}{c}\text { Nominal lithium } \\
\text { Concentration (mmol/l) }\end{array}$ & $\begin{array}{c}\text { Freeze-thaw } \\
\text { stability }\end{array}$ & $\begin{array}{c}\text { Long-term } \\
\text { stability }\end{array}$ & $\begin{array}{c}\text { Bench-top } \\
\text { stability }\end{array}$ & $\begin{array}{c}\text { Processed sample } \\
\text { stability }\end{array}$ \\
\hline 0.2 & $93.0 \%$ & $96.9 \%$ & $97.2 \%$ & $109.5 \%$ \\
0.8 & $99.4 \%$ & $99.9 \%$ & $101.5 \%$ & $100.1 \%$ \\
1.5 & $99.3 \%$ & $106.5 \%$ & $99.3 \%$ & $100.0 \%$ \\
\hline
\end{tabular}

Table 4. Comparison of analytical method with a reference flame photometric method and an ion-selective electrode method

\begin{tabular}{|c|c|c|c|c|c|c|}
\hline \multirow[b]{2}{*}{$\begin{array}{c}\text { Nominal lithium } \\
\text { concentration } \\
(\mathrm{mmol} / \mathrm{l})\end{array}$} & \multirow[b]{2}{*}{ Sample } & \multicolumn{5}{|c|}{ Calculated lithium concentration $(\mathrm{mmol} / \mathrm{l})$} \\
\hline & & $\begin{array}{c}\text { Sherwood } \\
410 \text { flame } \\
\text { photometer }\end{array}$ & $\begin{array}{c}\text { Jenway PFP7 } \\
\text { flame } \\
\text { photometer }\end{array}$ & Sample & $\begin{array}{c}\text { Sherwood } 410 \text { flame } \\
\text { photometer }\end{array}$ & $\begin{array}{c}\text { Ion-selective } \\
\text { electrode }\end{array}$ \\
\hline \multirow[t]{3}{*}{0.20} & 1 & 0.21 & 0.20 & 1 & 0.18 & 0.18 \\
\hline & 2 & 0.21 & 0.20 & 2 & 0.18 & 0.18 \\
\hline & 3 & 0.21 & 0.20 & 3 & 0.18 & 0.19 \\
\hline \multirow[t]{3}{*}{0.80} & 1 & 0.79 & 0.81 & 1 & 0.78 & 0.77 \\
\hline & 2 & 0.82 & 0.81 & 2 & 0.80 & 0.79 \\
\hline & 3 & 0.82 & 0.83 & 3 & 0.80 & 0.77 \\
\hline \multirow[t]{3}{*}{1.50} & 1 & 1.50 & 1.50 & 1 & 1.39 & 1.48 \\
\hline & 2 & 1.47 & 1.47 & 2 & 1.39 & 1.45 \\
\hline & 3 & 1.47 & 1.47 & 3 & 1.42 & 1.49 \\
\hline
\end{tabular}

\section{Analysis of patient samples}

The 240 patient samples analysed were of patients in the age range 18-73 years (Standard Deviation 12.13) where 129 (53.8\%) were male. Five samples $(2.1 \%)$ were below the LLOQ but the concentrations were above the calculated detection limit of 0.042 $\mathrm{mmol} / \mathrm{l}$. There were $24(10 \%)$ samples which gave a concentration reading of between the LLOQ and 0.4 $\mathrm{mmol} / \mathrm{l}$ (lower end of the range for maintenance therapy). The number of samples in the recommended therapeutic concentrations for maintenance therapy at $0.4 \mathrm{mmol} / \mathrm{l}$ and $1 \mathrm{mmol} / \mathrm{l}$ were $199(82.9 \%)$ and $12(5 \%)$ of the samples were above $1 \mathrm{mmol} / \mathrm{l}$ concentration [13].

\section{Discussion}

For the validation of the flame photometric method, first the matrix effect due to serum was analysed in order to determine if there is any effect of the biological matrix in sample analysis as the calibration plots for patient sample analysis is prepared with aqueous samples. Calibration plots are obtained with lithium spiked aqueous samples as it is uncomplicated, accurate and less time consuming. Aqueous calibration solutions prevent blockage of the flame photometer and ensure continuous operation of the instrument. Both aqueous and serum samples demonstrated matrix factors between 92.5\%-105.5\%. Therefore, the matrix effect observed was minimal. Santo et al have reported of the absence of a matrix effect between serum and aqueous media, which is similar to our findings [7]. The absence of a significant matrix effect is also evident as the two slopes of the lithium concentration verses response plots are similar in aqueous solution (Figure 1) and serum solution (Figure 2).

The accuracy of the method ranged at a maximum range of approximately $\pm 7 \%$ from the nominal concentration with precision. The long-term stability of the samples also did not change beyond approximately $\pm 7 \%$ from the nominal concentration. The freeze-thaw stability, bench top stability and processed sample stability were also within the acceptable 
percentage bias. Therefore, the stability and accuracy of results generated from our study is further confirmed. Samples in our laboratory are usually analysed once a week and these did not

The LLOQ used in this study was $0.2 \mathrm{mmol} / \mathrm{l}$. The matrix effect, accuracy, precision and stability of the data further validates the LLOQ used, as all accuracy, precision and stability data were within the stipulated guidelines. Of the 240 patient samples analysed 5 samples gave readings below the LLOQ. These values were above the lower limit of detection which can be calculated as 3.3 times the residual standard deviation of a regression line divided by the slope of the calibration curve giving a value of 0.042 $\mathrm{mmol} / \mathrm{l}[12]$.

In a study by Aliasgharpour et al which evaluated serum lithium concentrations with three analysers i.e., flame emission, flame atomic absorption and ion-selective electrode method, demonstrated that between-day precision was better for flame photometry compared to ion- selective electrode method and the atomic absorption method (CV\% of $1.3 \%$ versus $2.2 \%$ and $2.3 \%$ ) [5]. This study also obtained a significantly higher average lithium concentration for serum samples measured by ionselective electrode method than flame photometry [5]. A study which compared eight methods of serum lithium estimation which included five ionselective electrode methods and one colorimetric method, while using flame photometry and atomic absorption spectroscopy as reference methods, concluded that there is variability of the performance characteristics of the ion-selective electrodes [4]. Our study shows that both the flame photometric method and the ion-selective electrode method, which we used to compare our method, gives similar results to the flame photometric method used in the validation study.

In Sri Lanka serum lithium estimation is done by flame photometric methods and ion-selective electrode methods. The ion-selective electrode method is much simpler and rapid as it involves an automated system, which doesn't require any sample preparation. This method can be carried out with much lower serum sample volume compared to the flame photometric method. However, the ionselective electrode methods cost approximately Rs. 2000 per sample (approx. US \$13.3) while the flame photometric method costs approximately Rs. 500 (approx. US \$3.3) per sample. Therefore, the flame photometric method is highly cost-effective and gave reliable results in our setting.

In this study, we have conducted tests to cover the matrix effect, linearity of calibration curves, intraday accuracy and precision, long term stability, freeze-thaw stability, bench-top stability and show any significant temporal difference. These results prove that the reports generated by the flame photometric method with weekly analysis are reproducible.

processed sample stability. Flame photometric serum lithium estimation method employed at the Department of Pharmacology, Faculty of Medicine, University of Colombo has demonstrated accuracy, precision and stability in compliance with the guidelines for bioanalytical method validation parameters recommended by the European Medicines Agency [8]

Accuracy and reproducibility of laboratory results is a critical factor, which ensures patient safety. The results of the present study confirm the use of the flame photometric method as a suitable method for therapeutic drug monitoring of serum lithium in a resource limited setting such as Sri Lanka.

\section{Conclusions}

This study has shown that modified flame photometric method using the Sherwood 410 model to determine serum lithium concentrations at the Department of Pharmacology laboratory, is capable of producing accurate and reliable results. These results are comparable to an ion-selective electrode method employed in a leading local private sector clinical laboratory in Sri Lanka with ISO 15189 certification.

Funding source: Uthpali Mannapperuma was funded by the University of Colombo Doctoral Research Grant number AP/03/2011/PG/12

\section{Acknowledgments}

Authors wish to thank the Research Writing Support Program (RWSP), Faculty of Medicine, University of Colombo, Sri Lanka, and Author AID at INASP for writing assistance.

\section{References}

1. Malhi GS, Tanious M, Bargh D, Das P, Berk M. Safe and effective use of lithium. Australian Prescriber 2013;3:18-21

2. Yatham LN, Kennedy SH, Parikh SV, Schaffer A, Beaulieu S, Alda M, et al. Canadian Network for Mood and Anxiety Treatments (CANMAT) and International Society for Bipolar Disorders (ISBD) collaborative update of CANMAT guidelines for the management of patients with bipolar disorder: update 2013. Bipolar Disord 2013;15:1-44.

3. Ng F, Mammen OK, Wilting I, Sachs GS, Ferrier IN, Cassidy F, et al. The International Society for Bipolar Disorders (ISBD) consensus guidelines for the safety monitoring of bipolar disorder treatments. Bipolar Disord 2009;11:559-95.

4. Sampson M, Ruddel M, Elm RJ. Lithium Determinations Evaluated in Eight Analyzers. Clin 
Chem 1994;40:869-72.

5. Aliasgharpour M, Hagani H. Evaluation of lithium determination in three analyzers: flame emission, flame atomic absorption spectroscopy and ion selective electrode. N Am J Med Sci2009;1:244-6.

6. Bertholf R, Savory M, Winborne K, Hundley J, Plummer G, Savory J. Lithium determined in serum with an ion-selective electrode. Clin Chem 1988;34:1500-2.

7. Santo CEE, Carvalho TMJP. Determination of serum lithium: comparison between atomic emission and absorption spectrometry methods. Jornal Brasileiro de Patologia e Medicina Laboratorial. 2014;50:12-19.

8. European Medicine Agency. Guideline on bioanalytical method validation. London, United 